02

\title{
Влияние водорода на оптическую прозрачность слоев палладия
}

\author{
(C) В.А. Шутаев ${ }^{1}$, Е.А. Гребенщикова ${ }^{1}$, В.Г. Сидоров ${ }^{2}$, Ю.П. Яковлев ${ }^{1}$ \\ ${ }^{1}$ ФТИ им. А.Ф. Иофрфе РАН, \\ 194021 Санкт-Петербург, Россия \\ ${ }^{2}$ ООО АИБИ, \\ 194021 Санкт-Петербург, Россия \\ e-mail: vadimshutaev@mail.ru
}

Поступила в редакцию 26.09.2019 г.

В окончательной редакции 30.01.2020 г.

Принята к публикации 03.02.2020 г.

Исследована оптическая прозрачность слоев палладия в диапазоне длин волн $0.5-1.1 \mu \mathrm{m}$ на воздухе и в газовых средах, содержащих водород от 0.1 до 100 vol.\%. Слои изготовлены методом термического напыления в вакууме на стеклянных подложках. До толщины слоев порядка $450 \AA$ выполняется закон Бугера. В 100\% водороде при толщинах более $1200 \AA$ слои разрушаются. При некоторой концентрации водорода между 1 и 10\% наблюдается скачкообразное увеличение прозрачности слоев палладия, характерное для фазовых переходов первого рода. Скорость изменения прозрачности слоев при подаче водорода линейно увеличивается с увеличением концентрации водорода в газовой среде.

Ключевые слова: палладий, водород, оптическая прозрачность, фазовый переход.

DOI: $10.21883 /$ OS.2020.05.49316.276-19

\section{Введение}

Несмотря на то, что изучение взаимодействия водорода с палладием началось ещё в конце 19-го века, многие детали этой проблемы до сих пор остаются до конца не изученными, и исследования продолжаются [1]. Металл платиновой группы палладий обладает рядом уникальных свойств, благодаря которым находит применение в различных отраслях промышленности. Один объем палладия, например, способен поглотить до 1000 объемов водорода. Это свойство делает палладий основным претендентом на создание аккумуляторов водорода при производстве топливных элементов для энергоустановок водородной энергетики [2,3]. Также благодаря способности эффективно поглощать водород палладий используется в качестве активного элемента в структурах датчиков для регистрации водорода в газовой среде [4].

Внедренный в палладий водород вызывает деформацию кристаллической решетки, постоянная решетки увеличивается, изменяются механические, электрические и другие свойства палладия. С увеличением концентрации водорода в палладии изменяется фазовый состав материала, образуются гидриды палладия $\mathrm{PdH}_{x}$. Для кристаллического палладия при $x<0.02$ образуется $\alpha$ фаза, а при $x \geq 0.60-\beta$-фаза, при этом скачкообразно изменяется постоянная решетки, что характерно для фазовых переходов первого рода. При промежуточных значениях $x$ имеет место смесь фаз. Изменение фазового состава может сопровождаться изменением характера проводимости палладия от металлической к полупроводниковой $[3,5,6]$.
Оптимизация характеристик фотоэлектрического датчика водорода, создаваемого на основе структур $\mathrm{Pd} /$ оксид/InP [7-9], требует знания оптических свойств тонких слоев Pd. Нам известна лишь одна работа, в которой изучались оптические свойства слоёв $\mathrm{Pd}$ с толщинами менее $50 \mathrm{~nm}$, осаждённых на кварцевые подложки распылением Pd электронным пучком [10]. Настоящая работа посвящена исследованию влияния водорода на оптические свойства термически осаждённых на стеклянные подложки слоев палладия.

\section{Образцы и методика эксперимента}

Слои палладия изготовлены методом термического вакуумного напыления в замкнутом объеме при остаточном давлении $10^{-6}$ Torr на стеклянных подложках толщиной $1.5 \mathrm{~mm}$ (предметное стекло). Технология аналогична созданию слоев $\mathrm{Pd}$ при изготовлении структур $\mathrm{Pd} /$ оксид/InP [7-9]. Толщина слоев Pd измерялась на профилометре и на электронном сканирующем микроскопе и варьировала от 100 до $1300 \AA \AA$. Рентгенофазовый анализ показал, что Pd в слоях имеет аморфную структуру, и лишь при толщинах более $1000 \AA$ появляется кристаллическая фаза. Прозрачность слоев измерялась при комнатной температуре в диапазоне длин волн 0.5-1.1 $\mu \mathrm{m}$ с помощью монохроматора МДР-2 с кремниевым фотоприемником. Спектральная чувствительность фотоприемника учитывалась. Поглощение излучения в стеклянной подложке составляло не более $2 \%$ и также учитывалось при обработке спектров. Зависимость прозрачности слоев от времени измерена на длине волны $0.95 \mu \mathrm{m}$. Все измерения выполнены на воздухе 
и в газовых азотно-водородных смесях с содержанием водорода $0.1,1.0,4.0,10$ и $100 \mathrm{vol} . \%$.

\section{Результаты и их анализ}

На рис. 1 представлены спектры прозрачности $(T)$ слоев $\mathrm{Pd}$ различной толщины. Характер спектров и положение максимума прозрачности при $0.95 \mu \mathrm{m}$ не зависят от толщины образца.

На рис. 2 представлена измеренная на воздухе зависимость прозрачности слоев палладия от их толщины в максимуме прозрачности при $0.95 \mu \mathrm{m}$ в соответствии с классическим законом Бугера

$$
I=I_{0} \exp (-\alpha d)
$$

где $I_{0}$ и $I$ - интенсивность света, падающего на образец и прошедшего через него соответственно; $d-$ толщина образца; $\alpha-$ коэффициент поглощения для исследуемого вещества

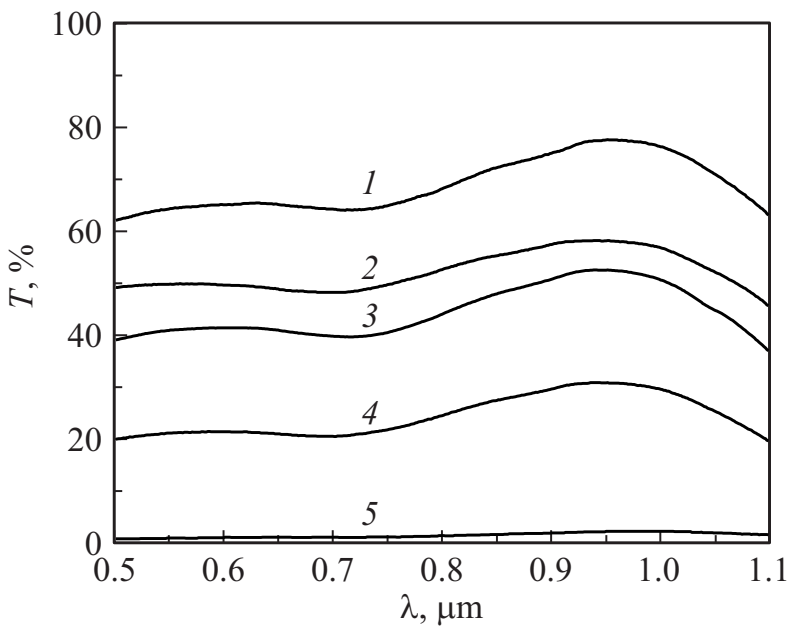

Рис. 1. Спектры прозрачности слоев $\mathrm{Pd}$ различной толщины, A: $1-110,2-370,3-440,4-620,5-780$.

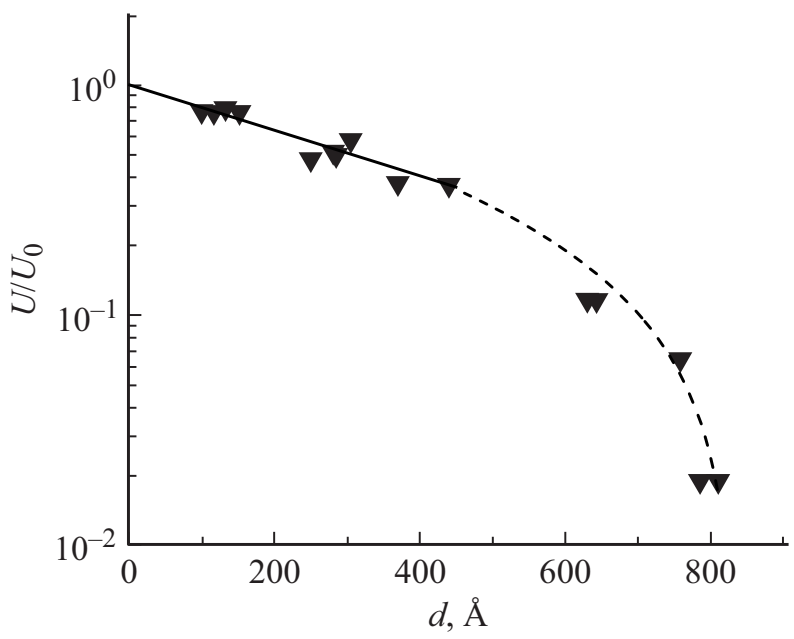

Рис. 2. Зависимость прозрачности слоев палладия от их толщины на длине волны $0.95 \mu \mathrm{m}$.

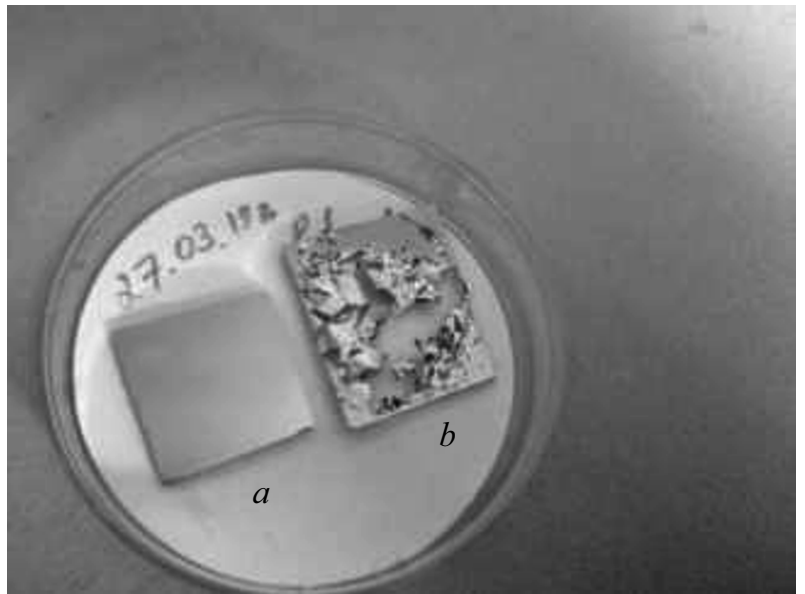

Рис. 3. Слои палладия, термически осажденные в вакууме на стеклянных подложках, после воздействия на них 100\% водорода; толщина слоев, $\AA: a-370, b-1300 \mu \mathrm{m}$.

В нашем случае закон Бугера используется в следующем виде:

$$
U=U_{0} \exp (-\alpha d)
$$

где $U_{0}$ и $U-$ показания фотоприемника без образца и при прохождении света через него соответственно; $d$ и $\alpha$ - толщина слоя $\mathrm{Pd}$ и коэффициент поглощения света в Pd. При этом предполагаем, что показания фотоприемника пропорциональны интенсивностям падающего и прошедшего через образец света.

Видно, что закон Бугера выполняется при толщинах слоев примерно до $d=450 \AA$ с постоянным коэффициентом поглощения $\alpha \sim 2.3 \cdot 10^{5} \mathrm{~cm}^{-1}$. При увеличении толщины слоя $\mathrm{Pd}$ более $450 \AA$ прозрачность слоев уменьшается нелинейно, закон Бугера не выполняется, а коэффициент поглощения монотонно увеличивается до $5 \cdot 10^{5} \mathrm{~cm}^{-1}$ при $d=800 \AA$ А. Это, по-видимому, связано с накоплением упругих напряжений в слоях при увеличении их толщины. Внешне это никак не проявляется, поверхность слоев на воздухе при всех толщинах остается зеркальной.

В 100\% водороде поверхность слоев остается зеркальной лишь до толщины $450 \AA$ и становится матовой при $d>450 \AA$. При толщинах слоев, больших $1200 \AA$, наблюдаются эффекты вспучивания и растрескивания слоя, а при толщине порядка 1300 А̊слои разрушаются (рис. 3). Отсюда следует, что можно ввести два параметра - две критические толщины слоев палладия, термически осажденных в вакууме на стеклянные подложки: при толщине более $450 \AA \AA$ нарушается закон Бугера, при толщине более $1200 \AA$ слои разрушаются.

Слои палладия с толщинами из области выполнения закона Бугера не изменяют своих свойств при многократном воздействии 100\% водородом. Спектры прозрачности этих слоев в газовой среде с различным содержанием водорода группируются на двух уровнях (рис. 4): при концентрациях водорода $0.1-1.0 \%$, когда 


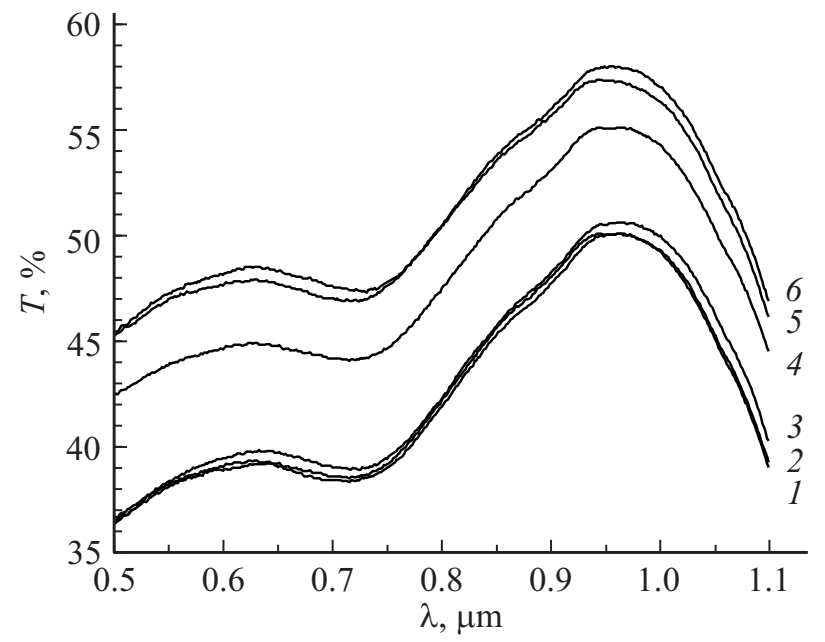

Рис. 4. Спектры прозрачности слоя палладия толщиной $370 \AA$, измеренные в газовых средах с концентрациями водорода, vol.\%: $1-0,2-0.1,3-1.0,4-4.0,5-10 ; 6-100$.

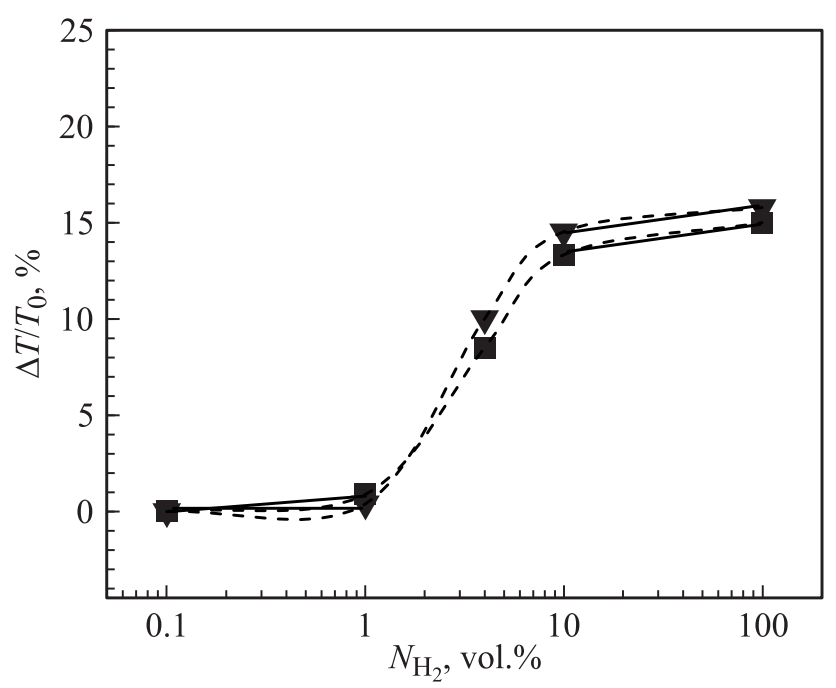

Рис. 5. Изменение прозрачности слоев Рd толщиной 120 и $370 \AA$ на длине волны $0.95 \mu \mathrm{m} . T_{0}-$ прозрачность слоев на воздухе.

прозрачность слоев практически не отличается от их прозрачности на воздухе, и при концентрациях водорода 10-100\%, когда прозрачность также остается практически постоянной, но увеличенной на $15 \%$ при некоторой концентрации водорода из области между 1.0 и $10 \%$ (рис. 5).

Подобного рода скачкообразные изменения свойств вещества характерны для фазовых переходов первого рода. В нашем случае резкое изменение оптической прозрачности палладия при подаче газовой среды, содержащей водород в области концентраций $0.1-10$ vol.\%, можно объяснить скачкообразным преобразованием гидридов $\alpha$-фазы в $\beta$-фазу, хотя полученная концентрация водорода, соответствующая изменению фаз, отличается от сообщаемой в литературе - $60 \%$ [5]. Причина различия может быть связана с аморфной структурой исследованных слоев $\mathrm{Pd}$, характерной для метода термического напыления в вакууме.

В спектрах прозрачности слоев палладия с толщинами из области, где не выполняется закон Бугера, наблюдаются аномалии (рис. 6). Прозрачность слоев в водороде не увеличивается, а уменьшается, и четкой зависимости от концентрации водорода в газовой среде не наблюдается (см. вставку на рис. 6). Слои с такими толщинами слоя палладия не рекомендуется использовать в структурах, предназначенных для детектирования водорода. Кроме того, исследована кинетика изменения

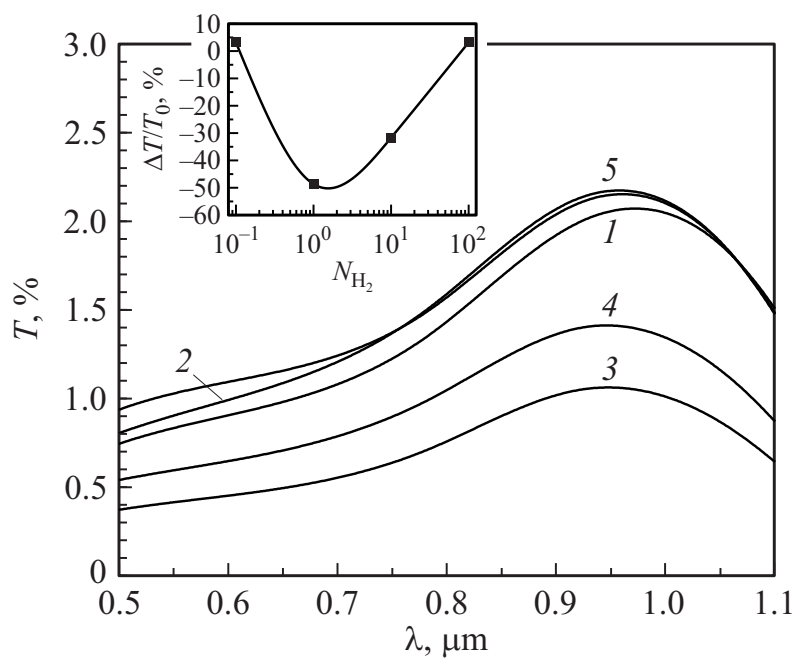

Рис. 6. Спектры прозрачности слоя палладия толщиной $780 \AA$ при различных концентрациях водорода, vol.\%: $1-0,2-$ $0.1,3-1.0,4-10,5-100$; на вставке - изменение прозрачности на длине волны $0.95 \mu \mathrm{m}$.

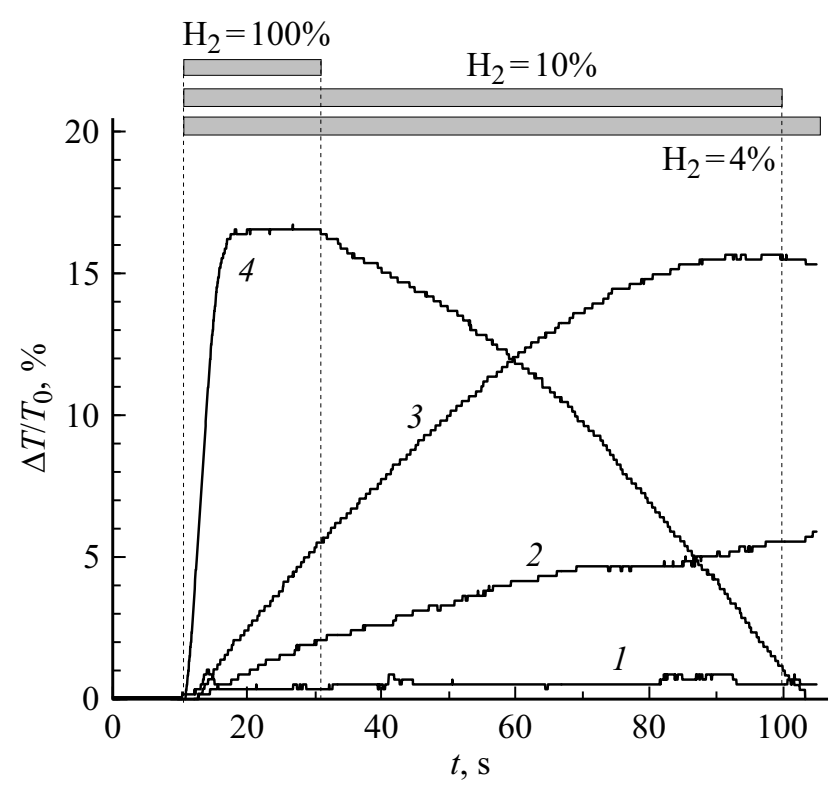

Рис. 7. Зависимость прозрачности от времени для слоя палладия толщиной $370 \AA \AA$ при различных концентрациях водорода, vol.\%: $1-1.0,2-4.0,3-10,4-100$. 


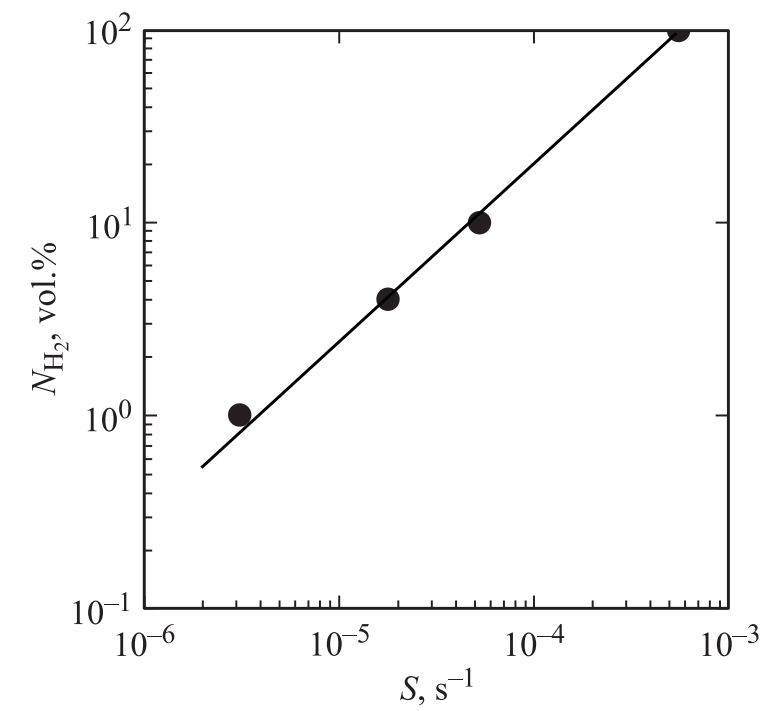

Рис. 8. Зависимость концентрации водорода в газовой среде от скорости изменения прозрачности.

оптической прозрачности слоев палладия в зависимости от концентрации водорода.

На рис. 7 представлены зависимости, характеризующие изменение прозрачности слоя палладия толщиной $370 \AA$ от времени при подаче газовых смесей с различной концентрацией водорода.

При этом концентрация водорода $\left(N_{\mathrm{H}_{2}}, \mathrm{vol} \%\right.$ \%) в газовой смеси и скорость увеличения прозрачности $(S$, $\mathrm{s}^{-1}$ ) слоя палладия связаны между собой линейной зависимостью (рис. 8). Данная зависимость может быть использована для определения концентрации водорода в окружающей среде.

\section{Заключение}

На стеклянных подложках изготовлены слои палладия с толщинами от 100 до $1300 \AA$ методом термического напыления в вакууме. Исследована их оптическая прозрачность при длинах волн $0.5-1.1 \mu \mathrm{m}$ на воздухе и в газовых азотно-водородных смесях с содержанием водорода от 0.1 до 100 vol.\%. Установлено, что закон Бугера выполняется для слоев с толщинами менее $450 \AA$, коэффициент поглощения при этом равен $2.3 \cdot 10^{5} \mathrm{~cm}^{-1}$. В 100\% водороде при толщинах более $1200 \AA$ слои разрушаются. Для слоев палладия с толщинами из области выполнения закона Бугера обнаружено скачкообразное увеличение оптической прозрачности при некоторой концентрации водорода между 1.0 и 10\%, что свидетельствует о фазовом переходе первого рода. Слои с толщинами более $450 \AA$, имеющие аномальные оптические характеристики, не рекомендуется использовать в структурах датчиков водорода. Зависимость концентрации водорода от скорости увеличения прозрачности палладия линейна и может быть использована для определения концентрации водорода в газовой среде.

\section{Конфликт интересов}

Авторы заявляют, что у них нет конфликта интересов.

\section{Благодарности}

Авторы выражают благодарность Н.В. Власенко за проведение напыления палладия, С.Ю. Беловой и С.И. Трошкову за помощь в измерении толщины слоев палладия.

\section{Список литературы}

[1] Ndaya C.C., Javahiraly N., Brioude A. // Sensors. 2019. V. 19. N 20. P. ??. doi 10.3390/s19204478

[2] Радченко Р.В., Мокрушин А.С., Тюльпа В.В. Водород в энергетике. Екатеринбург: Изд-во Урал. ун-та, 2014. 156 с.

[3] Некрасов Б.В. Основы общей химии. Т. 2. М.: Изд-во Химия, 1973. $382 \mathrm{c}$.

[4] Hubert T., Boon-Brett L., Banach G. // Sensors and Actuators B. 2011. V. 157. P. 329.

[5] Коротеев Ю.М., Гимранова О.В., Чернов И.П. // ФТТ. 2011. V. 53. № 5. C. 842.

[6] Товбин Ю.К., Вотяков Е.В. // ФТТ. 2000. Т. 42. № 7. C. 1158 .

[7] Шутаев В.А., Гребенщикова Е.А., Пивоварова А.А., Сидоров В.Г., Власов Л.К., Яковлев Ю.П. // ФТП. 2019. Т. 53. № 10. C. 1427.

[8] Гребенщикова Е.А., Салихов Х.М., Сидоров В.Г., Шутаев В.А., Яковлев Ю.П. // ФТП. 2018. Т. 52. № 10. С. 1183.

[9] Гребенщикова Е.А., Сидоров В.Г., Шутаев В.А., Яковлев Ю.П. // ФТП. 2019. Т. 53. № 2. С. 246.

[10] Avila J.I., Matelon R.J., Trabol R., Favre M., Lederman D. et al. // J. Appl. Phys. 2010. V. 107. N 2. P. 10. doi 10.1063/1.3272047 